\title{
Potential Impact of Existing Interventions and of Antiretroviral Use in Female Sex Workers on Transmission of HIV in Burkina Faso: A Modeling Study
}

\author{
Andrea Low, MD, PhD, * Nicolas Nagot, MD, PhD, $†$ Issouf Konate, MD, $\neq$ Nicolas Meda, MD, $\neq$ \\ Michel Segondy, PhD, $\uparrow$ Philippe Van de Perre, MD, PhD, $\uparrow$ Philippe Mayaud, MD,* \\ and Peter Vickerman, DPhilई
}

Background: The impact and cost-effectiveness of antiretroviral treatment (ART) as prevention is likely to vary depending on the local context. Burkina Faso has a concentrated mature HIV epidemic where female sex workers (FSW) are thought to have driven HIV transmission.

Methods: A dynamic HIV transmission model was developed using data from the Yerelon FSW cohort in Bobo-Dioulasso and population surveys. Compared with current ART provision [status quo (SQ)], the model estimated the proportion of HIV infections averted or incremental life-years gained per additional person-year of ART over 20 years for ART targeting different subgroups or expanding eligibility to all HIV-infected individuals compared with SQ.

Results: Modeling suggests that condom use within commercial sex has averted $40 \%$ of past HIV infections. Continuing SQ averts $35 \%-47 \%$ of new infections over 20 years compared with no ART. Expanding ART eligibility to all HIV-infected individuals and increasing recruitment ( $80 \%$ per year) could avert a further $65 \%$ of new infections, whereas targeting full-time FSW or all FSWs achieved less impact but was more efficient in terms of life-years

From the *Department of Clinical Research, London School of Hygiene and Tropical Medicine, London, United Kingdom; $\uparrow$ Departement de l'Information Medicale et Bacterologie-Virologie, Universite Montpellier-1 and CHU Montpellier, Montpellier, France; $\ddagger$ Unité de Recherche Santé de la Reproduction, VIH et Maladies Associées, Centre Muraz, Bobo-Dioulasso, Burkina Faso; and §School of Social and Community Medicine, University of Bristol, Bristol, United Kingdom.

This study was funded by France's Agence Nationale de Recherches sur le SIDA et les Hepatites (ANRS). Additional funding was provided by the Wellcome Trust and through the UK's Department for International Development (DFID)-funded Knowledge Programme on HIV/AIDS and STI and the Research Programme Consortium.

Presented at the 18th Conference on Retroviruses and Opportunistic Infections, March 3-27, 2011, Boston, MA, abstract \#773; and at the 20th Conference on Retroviruses and Opportunistic Infections, February 28-March 6, 2013, Atlanta, GA, abstract \#881.

The authors have no conflicts of interest to disclose.

Supplemental digital content is available for this article. Direct URL citations appear in the printed text and are provided in the HTML and PDF versions of this article on the journal's Web site (www.jaids.com).

Members of Yerelon Study Group are listed in the Appendix 1.

Correspondence to: Andrea Low, MD, PhD, London School of Hygiene and Tropical Medicine, Keppel Street, London WC1E 7HT, United Kingdom (e-mail: andrea_low@hotmail.com).

Copyright (C) 2015 Wolters Kluwer Health, Inc. All rights reserved. gained per 100 person-years of ART. Local HIV elimination is possible with expanded ART provision to FSWs but requires condom use within commercial sex to be maintained at high levels.

Conclusions: Increasing FSW recruitment onto ART could be a highly efficient method for reducing HIV transmission in concentrated epidemic settings but should not be undertaken at the expense of existing interventions for FSWs. Specialized clinics providing multiple interventions for FSWs should be a fundamental component of prevention in concentrated epidemics.

Key Words: antiretrovirals, female sex worker, Burkina Faso, treatment as prevention, modeling, HIV transmission

(J Acquir Immune Defic Syndr 2015;68:S180-S188)

\section{INTRODUCTION}

Despite evidence of high efficacy of antiretroviral treatment (ART) in reducing heterosexual transmission of $\mathrm{HIV}$, the population-level effectiveness of HIV treatment as prevention (TasP) is unclear. ${ }^{1}$ The randomized trial HPTN 052 confirmed observational studies that showed that ART initiation at higher $\mathrm{CD}^{+}$count thresholds had a pronounced impact on transmission in serodiscordant couples. ${ }^{2,3}$ Data from observational studies also support a reductive effect on transmission, although at a lesser magnitude than the $96 \%$ reduction observed in HPTN 052. One meta-analysis found a $42 \%$ reduction in transmission risk, ${ }^{4}$ whereas others found a $92 \%$ reduction. ${ }^{5,6}$ Results of observational studies have been highly heterogeneous, with estimates of impact including a $26 \%$ reduction in China, ${ }^{7}$ a $38 \%$ reduction in acquisition of HIV in those living in areas with high ART $(>40 \%)$ coverage compared with low $(<10 \%)$ in South Africa, ${ }^{8}$ and no impact in a cohort in Uganda. ${ }^{9}$

Factors influencing effectiveness remain unclear but likely include adherence to treatment and retention in care. ${ }^{10}$ There is concern that expansion of ART as a method of prevention and not just as a therapeutic intervention might overburden health systems, which struggle with diagnosing and treating those with advanced disease, particularly in settings of generalized epidemics. ${ }^{11,12}$ Such programs could lead to diversion of resources from established prevention programs and an increase in drug resistance, thus leading to suboptimal individual and public 
health outcomes. ${ }^{13,14}$ Modeling suggests that expanding ART treatment to those with a $\mathrm{CD}^{+}$count $<500$ cells per microliter would be cost-effective in a wide variety of settings, ${ }^{15,16}$ but little data from real world experience exist. Variations in the epidemiology of HIV might alter the costeffectiveness of TasP and warrant additional study. ${ }^{17,18}$

Female sex workers (FSW) remain an important HIV core group in many regions, such as West Africa. ${ }^{19-22}$ Results of trials of TasP targeting FSW are not yet available. ${ }^{23}$ Predictive models using data on sexual behavior and biological measures remain one of the most useful means of estimating the role of expanding treatment on HIV transmission. Models constructed around concentrated epidemics in Asia have found that the relative benefits of ART expansion in FSW are highly dependent on condom use and epidemic size. ${ }^{24,25}$ Few models have been constructed around FSW in West Africa, where successful targeted interventions have been in place since the 1990s, which could influence gains of ART expansion. ${ }^{26,27}$

Burkina Faso is one of several nations in which the incidence of HIV has declined, despite limited availability of ART until recently. ${ }^{28,29}$ The aim of this study was to model the impact of various ART prioritization strategies within the concentrated mature epidemic of Bobo-Dioulasso and to determine the most efficient strategy in terms of HIV infections averted (HIA) and life-years gained (LYG).

\section{METHODS}

\section{Model Description}

A deterministic compartmental model simulating heterosexual HIV transmission was developed using data from the Yerelon cohort of FSWs (ANRS 1222) in BoboDioulasso and from multiple population surveys. The cohort was established in 1998 to determine optimal interventions to minimize risk of HIV infection in highrisk women in Bobo-Dioulasso; it provided regular STI and HIV testing and treatment in an adapted public clinic. ${ }^{30-32}$ The program also promoted condom use throughout BoboDioulasso by using former FSWs as "peer educators" to disseminate information on condom negotiation and sexual health, and to distribute condoms at clinics and areas of sex work on a regular basis. ${ }^{33}$ It provided HIV and general medical care in the same setting, including ART from 2003 onwards.

The model categorizes individuals into subgroups on the basis of gender and sexual risk behavior based on behavioral data compiled from general and high-risk population surveys (Table 1): FSW stratified into occasional (OSW) or full-time sex workers (FTSW), male clients, and medium-risk (those reporting casual partnerships as well as main) and low-risk subgroups (those reporting main partnerships only), resulting in 7 subgroups (see Figure S1, Supplemental Digital Content, http://links.lww.com/QAI/A597). Commercial subgroups were defined based on the mean number of clients per year, ${ }^{30}$ as reported by women in the cohort database. Model details are provided in the Supplemental Digital Content (http://links.lww.com/QAI/A597).
The model assumes that once a person becomes infected with HIV, they are in the initial acute phase of infection (see Figure S2, Supplemental Digital Content, http://links.lww.com/QAI/A597). They then progress to the latent or chronic phases of infection, divided into the period when the $\mathrm{CD}^{+}$count is greater than 350 cells per microliter, followed by a period when the $\mathrm{CD} 4^{+}$count $<350$ cells per microliter but $>200$ cells per microliter, and another period when the $\mathrm{CD}^{+}$count $\leq 200$ cells per microliter. They then enter a short period with higher plasma viremia before experiencing clinical AIDS and death.

\section{Model Parameterization}

Biological parameters such as the HIV transmission probability and other natural history parameters were determined from a review of the literature using data from meta-analyses preferentially when available (see Table S1, Supplemental Digital Content, http://links.lww.com/QAI/A597). Progression rates through the HIV-related model compartments were based on data from the eART-linc collaboration, using data from African cohorts. ${ }^{56}$

Behavioral parameters such as condom use during last sex act were derived from cohort data, general population surveys, and from surveys among FSW and their clients (Table 1) ${ }^{30,39-41}$ Projections of condom use for years in which data were not available were calculated by fitting linear slopes to available estimates (see Figure S3, Supplemental Digital Content, http://links.lww.com/QAI/A597).

\section{ART Parameters}

ART was introduced into the model in 2004, for individuals with a $\mathrm{CD} 4^{+}$count $\leq 200$ cells per microliter and to those with a $\mathrm{CD} 4^{+}$count $<350$ cells per microliter after 2009 , at $25 \%$ yearly recruitment, which was calibrated to achieve coverage levels of $60 \%$ of those eligible by 2012 , based on national data. ${ }^{39,47}$ Yearly loss to follow-up (LTFU) was set at $6.5 \%$ as observed in this setting. ${ }^{50}$ ART was assumed to decrease infectiousness of HIV by $90 \%$ using data from observational studies, as it was believed that the efficacy from HPTN 052 was likely higher than in a nontrial setting. ${ }^{3,49,57}$ This was also informed by using data on genital shedding of HIV-1 for women on ART from the Yerelon cohort (see Figure S4, Supplemental Digital Content, http://links.lww.com/QAI/A597).$^{58}$ Lower efficacy estimates were considered in the sensitivity analysis. HIVinfected individuals on ART are assumed to progress through the same HIV progression compartments but with ART reducing the progression rate 4-fold when compared with ART-naive individuals. ${ }^{52-55}$ The impact on survival was varied in the sensitivity analysis due to a lack of data specific to Bobo-Dioulasso. We assumed that FSW and clients access ART at the same rate as the general population, based on similar CD4 counts at treatment initiation from several local surveys. ${ }^{39,59,60}$ While on ART, patients are LTFU at a rate assumed to be independent of $\mathrm{CD} 4^{+}$count and duration on ART and are returned to the untreated phase for the same $\mathrm{CD}^{+}$count compartment as they were in at the time of ART 
TABLE 1. Behavioral and Antiretroviral Intervention Parameters

\begin{tabular}{|c|c|c|c|}
\hline Behavioral Model Parameters & Female/FSW & Male/Client & Source \\
\hline Percentage of population FSW or clients & $2.0 \%(1.0 \%-3.0 \%)=\mathrm{NSW}$ & $5 \%-39 \%$ & $\begin{array}{l}\text { From }^{34,35} \text { for FSW and from a mapping exercise of } \\
\text { FSW in } 2010 \text {. Derived estimate for clients }\end{array}$ \\
\hline Ratio of clients to FSWs (F) & $5-13$ & & Range derived from surveys $s^{35-37}$ \\
\hline $\begin{array}{l}\text { Average duration of sex work or buying sex in } \\
\text { years }(1 / \sigma)\end{array}$ & & & Derived as a range using ${ }^{38-41}$ \\
\hline Clients & & $4-8$ & \\
\hline Average number of clients per year & & & Derived as a range from ${ }^{39}$ \\
\hline OSW $\left(c_{11}\right)$ & $24-104$ & & \\
\hline FTSW $\left(\mathrm{c}_{12}\right)$ & $312-2500$ & & \\
\hline \multicolumn{4}{|l|}{$\begin{array}{l}\text { Proportion of FSW reporting using condoms during } \\
\text { last sex act with clients in Bobo-Dioulasso }\end{array}$} \\
\hline $\begin{array}{l}\text { Frequency of casual partners per year amongst } \\
\text { medium and high-risk groups }\left(\mathrm{c}_{\mathrm{ca}}\right)\end{array}$ & $2-93$ & $2-7$ & $\begin{array}{l}{ }^{38} \text { Little data on the number of casual partners of FSW } \\
\text { or females, calculated from male reports }\end{array}$ \\
\hline $\begin{array}{l}\text { Yearly rate of increase in condom use with last casual } \\
\text { partner } 1993-2010\end{array}$ & $1.5 \%-2.5 \%$ & & Fit using data points in ${ }^{35,38,44}$ \\
\hline $\begin{array}{l}\text { Percentage of population reporting condom use with } \\
\text { main partner (generally married/cohabitating) }\end{array}$ & $0.7 \%-9.7 \%$ & & Range from surveys of general population ${ }^{35,44}$ \\
\hline \multicolumn{4}{|l|}{ Model ART intervention parameters } \\
\hline \multicolumn{4}{|l|}{ Year ART introduced } \\
\hline $\mathrm{CD} 4^{+}$count $<200$ or WHO stage 3 or 4 & 2004 & & Refs. $39,45,46$ \\
\hline $\mathrm{CD}^{+}$count $<350$ or WHO Stage 3 or 4 & 2009 & & Refs. 47,48 \\
\hline $\begin{array}{l}\text { Relative HIV transmission probability while on } \\
\text { ART compared with the transmission probability } \\
\text { if untreated }(\Phi)\end{array}$ & 0.10 & & $\begin{array}{l}\text { Using }{ }^{2,3,6} \text { but weighted lower due to evidence of lower } \\
\text { viral suppression }{ }^{45} \text { and data from West Africa }{ }^{49}\end{array}$ \\
\hline
\end{tabular}

cessation. Individuals can reinitiate ART at the same rate as they initiate ART.

\section{Model Calibration}

Parameters with significant uncertainty were assessed in a quasi-Bayesian framework, whereby they were allowed to vary within a specified prior distribution reflecting the range of likely estimates. ${ }^{61}$ Latin hypercube sampling was performed to randomly generate 750,000 parameter sets from these ranges. Each model run using these parameter sets was compared with existing data on HIV prevalence from cross-sectional surveys of OSW and FTSW and clients in 1994, overall FSW prevalence from surveys in 1990, 1999, and 2003, and from general population estimates in 2000 (see Table S2, Supplemental Digital Content, http://links.lww.com/QAI/A597). For all data used in fitting, the $95 \%$ confidence intervals were widened by adding a relative $\pm 10 \%$ to each because of uncertainty in the data source. Parameter sets were accepted as a fit (or

S182 I www.jaids.com "posterior" distribution) if the predicted prevalence simultaneously fell within the widened $95 \%$ confidence intervals of each estimate. Data were not fit for time points after 2004; however, parameter sets were excluded if they showed an increase in HIV prevalence in the general population after 2004, to correspond with data from national surveys. The posterior parameter sets were used for all simulations and were used to calculate a median estimate for all outcomes.

\section{Population Attributable Fraction Calculations}

The relative contribution of FTSW, OSW, and overall FSW populations to new infections in the whole population was calculated using bidirectional population attributable fractions $(\mathrm{PAF})$. The transmission in commercial partnerships was set to 0 for either OSW or FTSW or both, and their clients for 5-year periods, done in separate simulations. The number of incident cases in the total population was averaged over each set of simulations and was then

Copyright (c) 2015 Wolters Kluwer Health, Inc. All rights reserved. 
compared with the number of new cases in the original model. The following equation was used:

$$
\begin{aligned}
\mathrm{PAF}_{\mathrm{FSW}}= & \left(1-\text { Incident }_{\text {Cases }} \text { noFsW } / \text { Incident } \text { Cases }_{\text {original }}\right) \\
& \times 100 \%
\end{aligned}
$$

\section{Simulations}

Different interventions using ART were modeled beginning in 2014 and compared with the status quo (SQ) scenario of a yearly $25 \%$ recruitment onto ART of all eligible $\left(\mathrm{CD}^{+}{ }^{+}\right.$count $<350$ cells $\left./ \mu \mathrm{L}\right) \mathrm{HIV}$-infected individuals. The modeled interventions targeted all HIV-infected FSW, by typology (FTSW and OSW), or the entire population assuming increased eligibility and $80 \%$ recruitment onto ART per year. For scenarios targeting different subgroups, the ART recruitment rates for other subgroups were maintained at the level of the SQ scenario. The impact of each scenario was measured over 20 years in terms of percentage of HIA (\%HIA) and efficiency as LYG per 100 additional person-years of ART (PYAs) among the entire population, compared with SQ. This time frame was selected to allow the accumulation of health benefits in terms of LYG and comparability to recent modeling analyses. ${ }^{15}$

For the scenario targeting all FSW, the contribution of each uncertainty parameter to the variation in \%HIA over 20 years was estimated using linear regression analysis of covariance, where the percentage of the sum of squares attributable to each parameter was calculated to determine its impact on overall uncertainty.

\section{Sensitivity Analysis}

For the FSW-targeted ART scenario, the model was run for a number of univariate sensitivity analyses to assess how impact and efficiency would vary under different assumptions for the extension in survival attributable to ART ( 3 or 5 fold decrease in progression) or double the yearly ART dropout rates $(13 \%)$. Projections were compared with the SQ scenario, calibrated assuming the same change in parameters. We also examined scenarios assuming different efficacies of ART for reducing HIV infectivity, either based on an observational study from China (26\% reduction $)^{7}$ or an alternative estimate (58\% reduction) produced using data on genital HIV-1 RNA shedding from the Yerelon cohort (see Figure S4, Supplemental Digital Content, http://links.lww.com/QAI/A597). ${ }^{58}$

Additionally, because there is evidence from our cohort and Benin that there can be poorer virological suppression in FSWs than the general population, ${ }^{45,62}$ we considered a scenario where the efficacy of ART in reducing infectivity was lower in FSW (58\% reduction) than for other subgroups (90\% reduction). Finally, we considered how the impact and efficiency of targeting ART to FSW would vary if condom use had reached lower levels (70\%) among FSWs by 2014 . For these scenarios, we did not refit the model but allowed the epidemic to increase because of the lower levels of condom use.

\section{RESULTS}

Of 750,000 iterations, there were 240 model fits to HIV prevalence data among FSWs and 24 fits to HIV prevalence data including the general population that also displayed a decreasing prevalence by 2010. Table S3 (see Supplemental Digital Content, http://links.lww.com/QAI/A597) compares the posterior ranges for the model fits to their respective prior ranges. The model projections of HIV prevalence over time suggest that the HIV epidemic in Bobo-Dioulasso increased rapidly among high-risk groups in the 1980s (Fig. 1A), during which rates of condom use were negligible, peaked in the early 1990s, and then gradually decreased. Similar trends are projected for the general population (Fig. 1B). The model
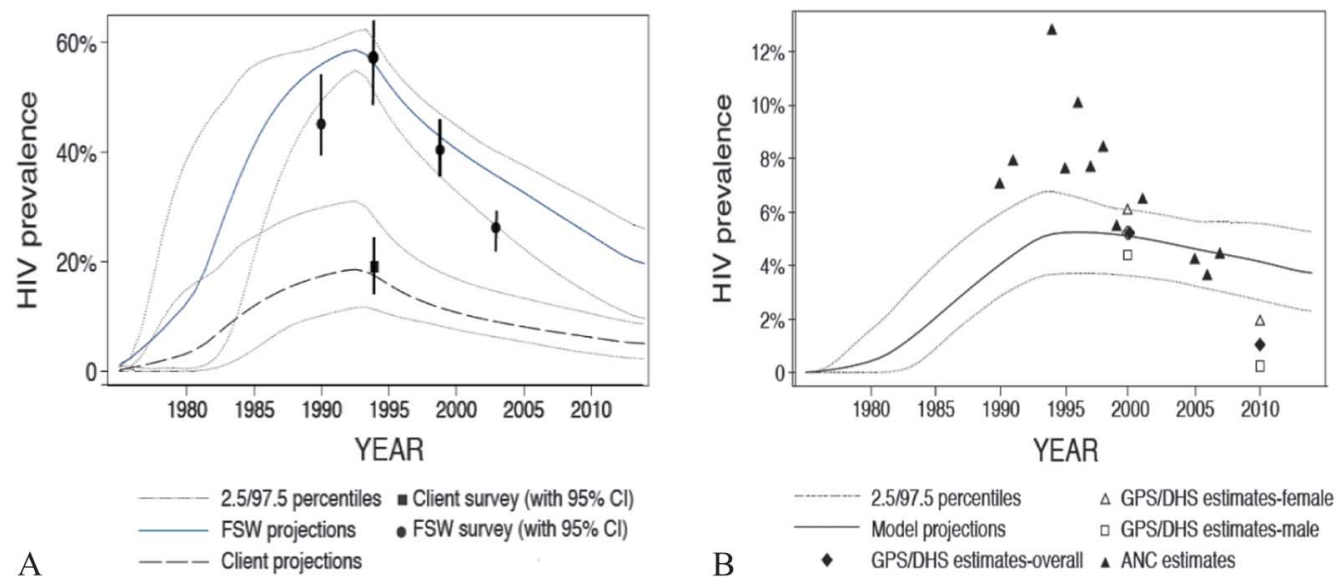

FIGURE 1. Model fit projections of HIV prevalence and data estimates for FSWs and their clients (A) and overall (B) populations. Note the different scales on the $y$-axis. The symbols and bars represent measured prevalence in (A) clients and sex workers and (B) the general population from surveys, ANC surveillance, and from the DHS 2010, limited to the Hauts-Bassin region and including rural areas. The lines represent median fits and $2.5 \%$ and $97.5 \%$ percentiles from the 24 fitted simulations. GPS, general population survey; DHS, demographic and health survey. 
estimates that 34,259 (range, 25,512-40,127) HIV cases occurred in Bobo-Dioulasso since the onset of the epidemic to 2014. The model's posterior estimated condom use at last sex act was $87.1 \%$ (95\% confidence interval [CI]: 82.5 to 95.0$)$ in commercial partnerships, $35.4 \%$ (95\% CI: 29.0 to 43.5 ) in casual partnerships, and $4.5 \%$ (95\% CI: 3.5 to 5.5$)$ in main partnerships by 2010 (see Figure S3, Supplemental Digital Content, http://links.lww.com/QAI/A597).

In the absence of any prevention interventions, namely any increase in condom use, ART coverage, or male circumcision (MC; coverage estimated to be $90 \%$ ), the model suggests that HIV prevalence would have been $10 \%-32 \%$ overall and $68 \%-82 \%$ in FSW in 2014 (see Figure S5, Supplemental Digital Content, http://links.lww.com/QAI/A597). Promotion of condom use averted $31 \%-53 \%$ of HIV infections during this period. The provision of ART since 2004 was estimated to have averted $2 \%-8 \%$ of cases and MC averted $36 \%-62 \%$.

\section{PAF due to Commercial Sex}

Model projections suggest that a large portion of incident HIV infections in this setting are attributable to commercial sex, with this being the greatest in 1985-1990 when $75 \%-88 \%$ of infections are attributable to FSW. This declined to 39\% between 1995 and 2010, as condom use increased in commercial sex (see Figure S6, Supplemental Digital Content, http://links.lww.com/QAI/A597). Most incident infections are due to FTSW (PAF $=60 \%-70 \%$ ) during the early phase of the epidemic, but the proportion approaches that of OSW by 2010 (PAF $=10 \%-20 \%)$, due to higher condom use in FTSW than OSW.

\section{Future Impact and Efficiency of ART Over 20 Years}

The continuation of the SQ scenario will avert 35\%$47 \%$ of infections compared with stopping ART over the next 20 years if condom use remains at 2010 levels, and local HIV elimination (defined as reducing HIV incidence to less than 1 infection per 1000 person-years) would be achieved by 2037 (Fig. 2). The most rapid decline in incidence is achieved by increasing recruitment of all HIV-infected individuals onto ART (54-71\%HIA compared with SQ) with local elimination being achieved by 2016 . If FSW are targeted, with $80 \%$ of HIV-infected FSWs recruited each year, then a smaller impact (4-38 \%HIA) is achieved, with local elimination occurring by 2027 .

Figure 3 and Table S4 (see Supplemental Digital Content, http://links.lww.com/QAI/A597) present the impact and efficiency (LYG and HIA/100 PYA) of different ART scale-up scenarios. Although expanding ART recruitment to $80 \%$ of all HIV-infected individuals has the largest impact of all scenarios considered, it is much less efficient (55 LYG/100 PYA) than targeting all FSWs (98 LYG/100 PYA) or FTSW (251 LYG/100 PYA) at the same recruitment rate. Interestingly, targeting OSW was not substantially more efficient than targeting everyone.
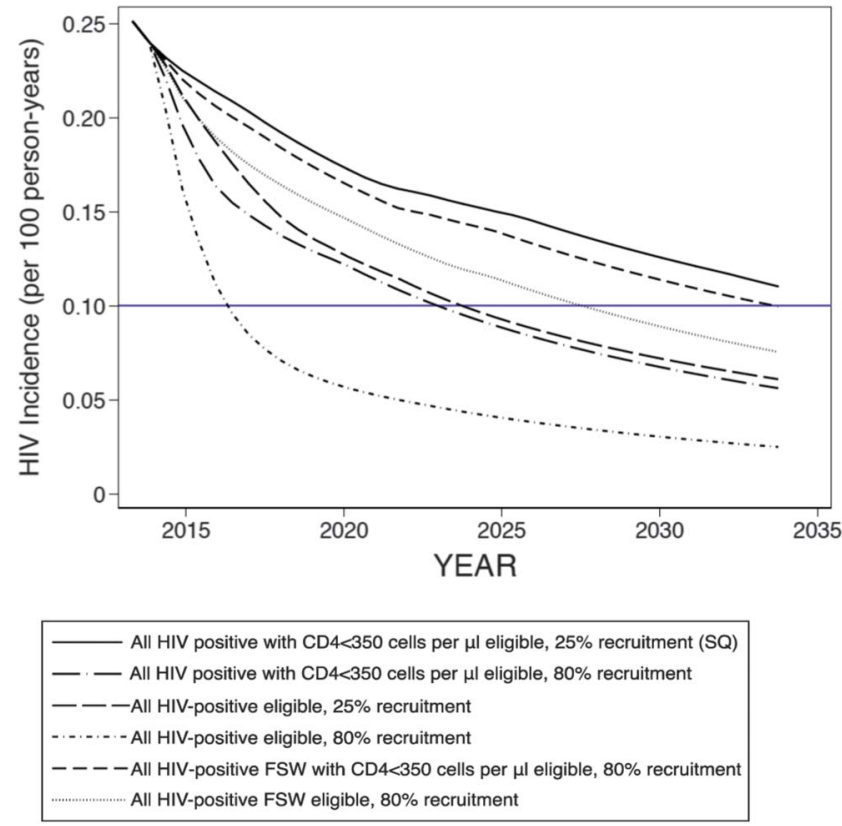

FIGURE 2. Projected overall annual HIV incidence rates for scenarios of eligibility and recruitment onto ART. The line represents the threshold for elimination $(<1$ case per 1000 person-years).

\section{Sensitivity Analysis}

Figure 4 and Table S5 (see Supplemental Digital Content, http://links.lww.com/QAI/A597) present the effect of varying assumptions on the projected impact and efficiency of scaling up ART to $80 \%$ recruitment of infected FSWs each year. Assuming a reduced effect of ART on infectivity $(58 \%$ vs. $90 \%$ ) reduces the \%HIA by two-thirds and LYG/100 PYAs by half, compared with the FSW recruitment scenario. If the efficacy of ART is reduced further to $26 \%$, little impact is achieved. In the scenario with differential efficacy of ART in reducing infectivity among FSWs and the general population, impact is reduced by $57 \%$ and efficiency by $45 \%$. Different assumptions for the efficacy of ART for increasing survival do not significantly change the estimated impact or efficiency of ART. Finally, increasing the rate of LTFU for all individuals on ART reduces the LYG but also reduces the years of ART after they have left sex work and therefore increases efficiency.

If we assume that commercial condom use (defined as condom use at last commercial sex act between a FSW and client) had reached lower levels in this setting, the incremental impact and efficiency of scaling up of ART among FSW increases. However, targeting ART to FSWs can no longer achieve elimination by 2034 . Elimination is not achieved by 2034 for any targeted ART scenario with $<82 \%$ commercial condom use or with $<57 \%$ commercial condom use if targeting ART to all HIV-infected individuals.

Analysis of covariance determined that the largest proportion of variation in \% $\mathrm{HIA}$ for the scenario where $80 \%$ of infected FSWs are recruited onto ART each year is due to uncertainty in the yearly number of clients for FTSW

Copyright (c) 2015 Wolters Kluwer Health, Inc. All rights reserved. 

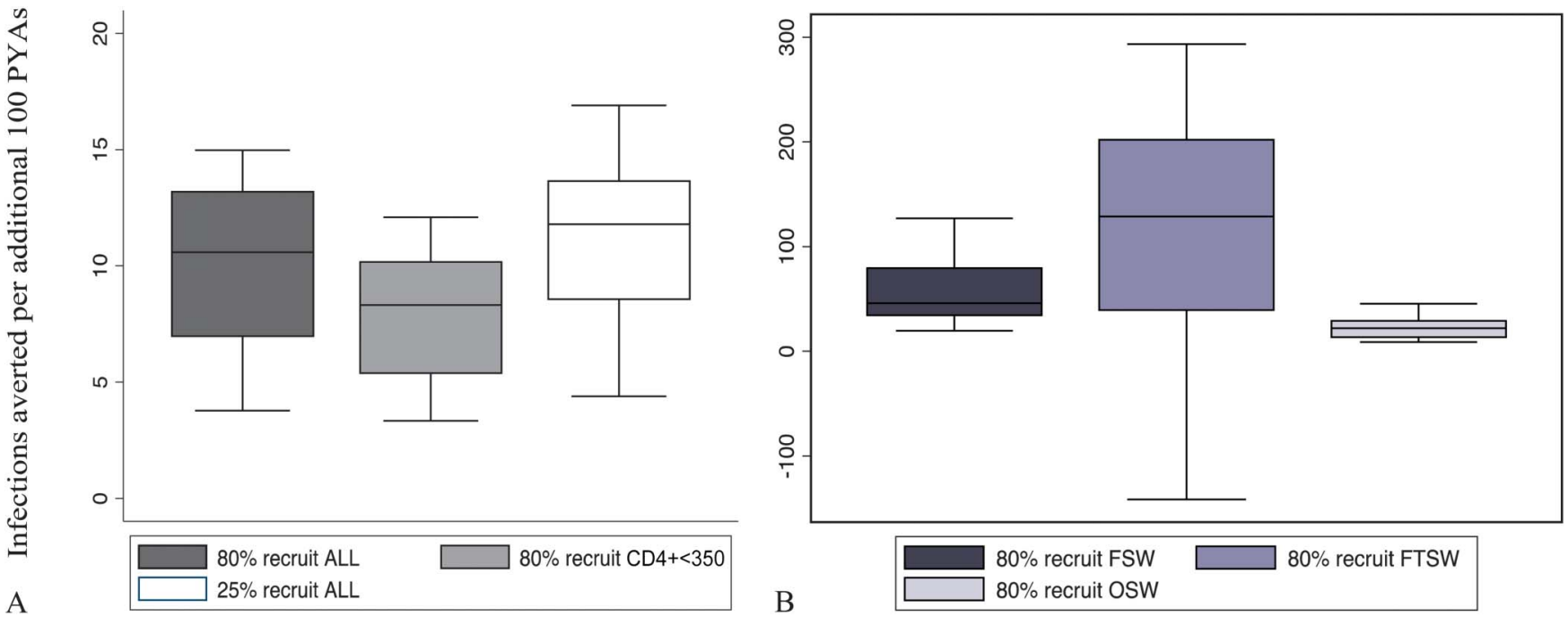

FIGURE 3. Efficiency of ART scenarios in averting new HIV infections compared with the SQ scenario. Note the different $y$-axis scales for $A$ and $B$. Each box represents the median and range of modeled impacts for recruiting (A) $80 \%$ or $25 \%$ of all HIVinfected individuals or increasing recruitment to $80 \%$ of all subgroups with a CD4 ${ }^{+}$count $<350$ cells per microliter or (B) $80 \%$ of all FSW, FTSW, or OSW regardless of CD4+ count onto ART each year. Negative values are a result of fewer years predicted for ART for some parameter sets compared with the SQ, implying very good efficiency.

$(14.4 \%)$, the cofactor increase in infectivity during acute infection $(13.7 \%)$, and the rate of condom increase for casual partnerships from 1994 to $2010(13.0 \%)$.

\section{DISCUSSION}

Although models have considered the impact of targeting ART among FSW populations in Asia, ${ }^{15,24,25}$ this is the first study to estimate the impact of targeting TasP to different typologies of FSWs in West Africa. Burkina Faso has a diminishing incidence of HIV, and although the prevalence in the general population was more than $3 \%$ in the $1990 \mathrm{~s}$, it now has a national prevalence close to $1 \% .^{26,48}$ This decline is mirrored in the FSW population in Bobo-Dioulasso where the prevalence has declined from $57.2 \%$ in $1994^{40}$ to $20.4 \%$ in $2010 .{ }^{38}$ This occurred within the context of expanded condom availability and syndromic management of STIs, both scaled up during the $1990 \mathrm{~s} .^{28,63}$ Our model attributes $40 \%$ of the historical reduction in HIV prevalence to the expansion in condom use, reflected in the decrease in HIV transmission attributable to FSWs, from more than $70 \%$ in the late 1980 s to less than $50 \%$ of new infections after 1995 . The model also suggests that HIV prevalence would have been much higher without the high coverage of $\mathrm{MC}$, which is traditionally practiced in Burkina Faso, and that ART so far has had little impact on the epidemic because of low coverage rates.
FIGURE 4. Sensitivity analysis of varying model assumptions on efficiency and impact of ART expansion in FSW (to $80 \%$ of all HIV-positive FSW per year) in terms of the percent deviation in LYG/100 PYAs and \%HIA from 2014 to 2034, compared with baseline impact projections. \%HIA, percent of HIV infections averted. All scenarios recruit FSW at $80 \%$ per year onto ART, with commercial condom use at $90 \%$, and LTFU of $6.5 \%$ per year, unless otherwise indicated. Each scenario is compared with the SQ recruitment, with the same parameters varied as in the FSW-targeted scenario, to calculate the LYG per 100 additional PYAs. Percent change is then calculated as the percent deviation in LYG estimate from the baseline FSW-targeted scenario.

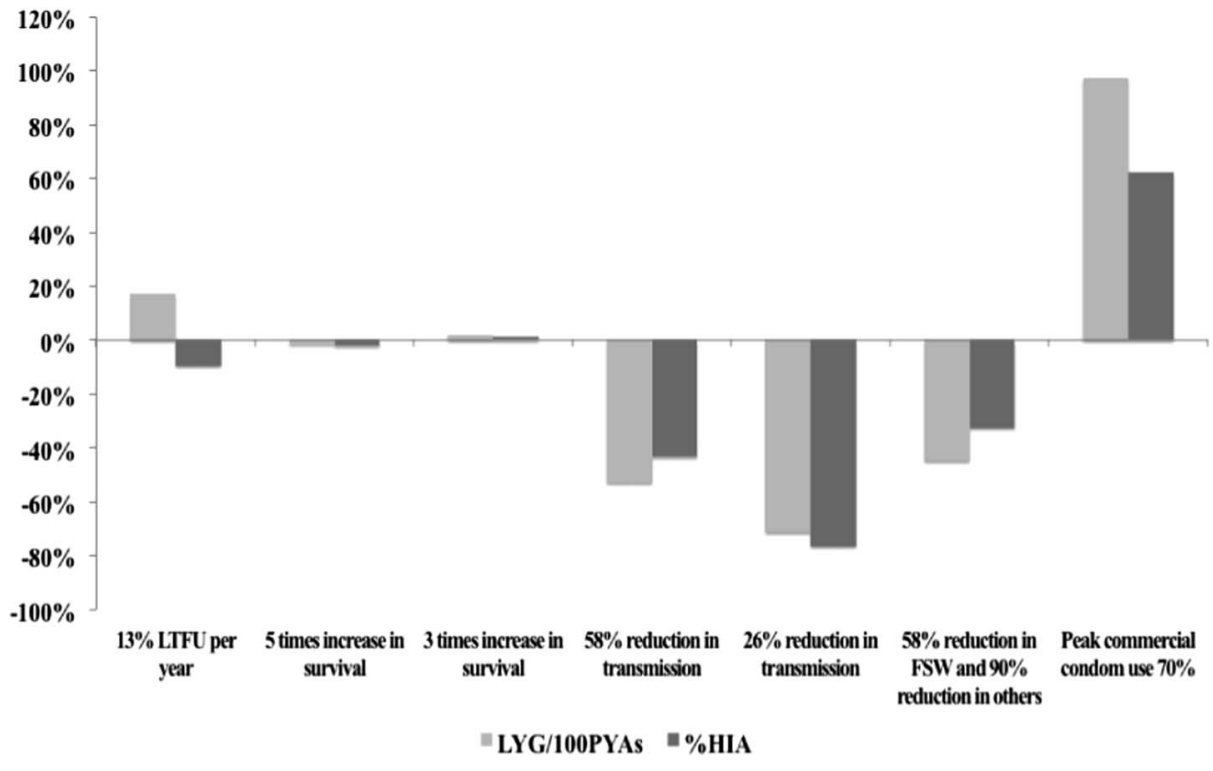


Similar declines in HIV prevalence have been observed in many FSW populations in the region, some in countries directly targeting FSW with interventions combining STI and behavioral components ${ }^{64-66}$ and others where the decline occurred independently of programmatic changes, possibly because of the natural history of the epidemic. ${ }^{67-70}$

Current and expanded ART provision in this setting could achieve considerable impact, with most HIV infections being averted when $80 \%$ of all HIV-infected individuals are recruited onto ART each year, resulting in rapid elimination. However, this strategy is considerably less efficient than targeting FTSW or all FSW and requires a much larger investment in ART (a 96\% increase in provision over targeting FSW) and wide-scale HIV counseling and testing. Targeting FSW is more feasible, as most FSWs in Burkina Faso report having been tested for HIV in the past year $(83 \%$ in 2010), whereas less than $30 \%$ of the general population report ever being tested. ${ }^{38,71}$ However, FSWs can be difficult to reach, and care is therefore best offered within specialized clinics, where staff can provide multiple interventions in a non-judgmental environment. ${ }^{39,72}$

In our model, the efficiency of expanding ART to FSWs is higher if condom use is lower in commercial settings. However, in this heightened epidemic scenario, just scaling up ART among FSWs can no longer achieve elimination. This emphasizes the importance of achieving high levels of condom use among FSWs as a fundamental primary intervention for controlling HIV transmission, ${ }^{27}$ and illustrates the importance of preventing behavioral risk compensation as has occurred in other populations, such as men who have sex with men. ${ }^{1,73}$ Indeed, studies from South Africa have shown that diverting funds from other prevention activities can lead to an increase in incidence despite expanding ART coverage. ${ }^{74}$ However, studies of African FSWs have shown that sexual risk taking in women on ART can be minimized if behavioral change programs are maintained. ${ }^{75-77}$

Even when assuming a more conservative efficacy of ART in reducing HIV infectivity, targeting ART towards FSW still prevents more infections than the current policy. Although targeting OSW reduces efficiency due to their lower $\mathrm{PAF}$, it is likely that their inclusion would be easier to implement. Although survey data suggest few transitions from OSW to FTSW, it is likely that a FSW's client volume fluctuates and so the distinction between full and occasional sex work may be blurred and difficult to assess in the field.

\section{Limitations of the Model}

Our modeling analysis had limitations. First, the model did not include the full heterogeneity of the sexually active subgroups or preferential like-with-like sexual mixing between individuals of the same sexual risk because of a paucity of data in this setting. This might be a contributing factor to the high HIV prevalence predicted in 2010. Furthermore, after 2000, there was little HIV prevalence data from Bobo-Dioulasso that could be used for model fitting, with the demographic and health survey aggregating data across the region. However, despite the higher prevalence predicted by our model in 2010 as compared with the demographic and health survey estimates,

S186 | www.jaids.com this is consistent with surveillance data from antenatal clinics in Bobo-Dioulasso, where prevalence was $4.2 \%$ (95\% CI: 3.9 to 4.5 ) in $2007 .^{78}$ Second, although the model assumed more conservative efficacy estimates for the impact of ART on HIV infectivity, our results should be considered cautiously because there are little data on the efficacy of ART in high-risk populations. Instead, data on genital shedding of HIV from FSWs in this setting was used to estimate the likely efficacy of ART, but this method has not been validated; nor is it not known if low levels of HIV-1 RNA detected in women on ART represents infectious virus. Third, we did not include the possible development of antiretroviral drug resistance in our model, which could diminish impact or increase future costs. ${ }^{15}$ Finally, we allowed individuals lost to follow-up to be recruited back onto ART, and so our projections could be optimistic.

In conclusion, our modeling suggests that targeting ART to FSWs in concentrated epidemic settings, such as in Bobo-Dioulasso, could be a highly efficient strategy for reducing HIV transmission and supports intervening in highrisk groups early in younger epidemics. The success of such an intervention depends on continuing investment in condom promotion. However, it is important to acknowledge that targeting FSWs may require more investment in increasing access to care through dedicated clinics, including adherence support, than for the general population, which could reduce efficiency gains seen in this model. ${ }^{79}$ Furthermore, structural and legal barriers to FSW gaining access to care are considerable in most countries, and addressing these will be imperative to see any real success of targeted TasP. ${ }^{19,72}$

\section{ACKNOWLEDGMENTS}

The authors wish to thank the women and the organizations of persons living with HIV/AIDS ("Yérelon," "Espoir et Vie," Centre "Solidarité Action Sociale" and "Espoir pour Demain") who participated in this study and staff at Service d'Hygiène, Bobo-Dioulasso, Burkina Faso. The authors also want to thank Charlotte Huet, Dramane Kania, Diane Valea and Antoinette Kabore for their invaluable assistance.

\section{REFERENCES}

1. Wilson DP. HIV treatment as prevention: natural experiments highlight limits of antiretroviral treatment as HIV prevention. PLoS Med. 2012;9: e1001231.

2. Donnell D, Baeten JM, Kiarie J, et al. Heterosexual HIV-1 transmission after initiation of antiretroviral therapy: a prospective cohort analysis. Lancet. 2010;375:2092-2098.

3. Cohen MS, Chen YQ, McCauley M, et al. Prevention of HIV-1 infection with early antiretroviral therapy. $N$ Engl J Med. 2011;365:493-505.

4. Anglemyer A, Rutherford G, Horvath HT, et al. Antiretroviral therapy for prevention of HIV transmission in HIV-discordant couples. Cochrane Database Syst Rev. 2013;4:1-53.

5. Baggaley RF, White RG, Hollingsworth TD, et al. Heterosexual HIV-1 infectiousness and antiretroviral use: systematic review of prospective studies of discordant couples. Epidemiology. 2013;24:110-121.

6. Attia S, Egger M, Muller M, et al. Sexual transmission of HIV according to viral load and antiretroviral therapy: systematic review and metaanalysis. AIDS. 2009;23:1397-1404.

7. Jia Z, Ruan Y, Li Q, et al. Antiretroviral therapy to prevent HIV transmission in serodiscordant couples in China (2003-11): a national observational cohort study. Lancet. 2012;382:1195-1203.

Copyright (c) 2015 Wolters Kluwer Health, Inc. All rights reserved. 
8. Tanser F, Barnighausen T, Grapsa E, et al. High coverage of ART associated with decline in risk of HIV acquisition in rural KwaZulu-Natal, South Africa. Science. 2013;339:966-971.

9. Birungi J, Wang $\mathrm{H}$, Ngolobe $\mathrm{M}$, et al. Lack of effectiveness of antiretroviral therapy (ART) as an HIV prevention tool for serodiscordant couples in a rural ART program without viral load monitoring in Uganda. In: Society IA, ed. 19th International AIDS Conference. Washington, DC; July 22-27, 2012.

10. Das M, Chu PL, Santos GM, et al. Decreases in community viral load are accompanied by reductions in new HIV infections in San Francisco. PLoS One. 2010;5:e11068.

11. Rosen S, Fox MP. Retention in HIV care between testing and treatment in sub-Saharan Africa: a systematic review. PLoS Med. 2011;8: e1001056

12. UNAIDS 2010. Towards universal access: scaling up priority HIV/AIDS interventions in the health sector. Progress report 2010. Available at: http://www.who.int/hiv/pub/2010progressreport/en/. Accessed May 3, 2012.

13. Wagner BG, Blower S. Universal access to HIV treatment versus universal "test and treat": transmission, drug resistance \& treatment costs. PLoS One. 2012;7:e41212.

14. Cohen MS, Smith MK, Muessig KE, et al. Antiretroviral treatment of HIV-1 prevents transmission of HIV-1: where do we go from here? Lancet. 2013;382:1515-1524.

15. Eaton J, Menzies N, Stover J, et al. Health benefits, costs, and costeffectiveness of earlier eligibility for adult antiretroviral therapy and expanded treatment coverage: a combined analysis of 12 mathematical models. Lancet Glob Health. 2014;2:e23-e34.

16. Walensky RP, Ross EL, Kumarasamy N, et al. Cost-effectiveness of HIV treatment as prevention in serodiscordant couples. N Engl J Med. 2013; 369:1715-1725.

17. Vickerman P, Terris-Prestholt F, Delany S, et al. Are targeted HIV prevention activities cost-effective in high prevalence settings? Results from a sexually transmitted infection treatment project for sex workers in Johannesburg, South Africa. Sex Transm Dis. 2006;33 (10 suppl):S122-S132.

18. Vickerman P, Watts C, Delany S, et al. The importance of context: model projections on how microbicide impact could be affected by the underlying epidemiologic and behavioral situation in 2 African settings. Sex Transm Dis. 2006;33:397-405.

19. Baral S, Beyrer C, Muessig K, et al. Burden of HIV among female sex workers in low-income and middle-income countries: a systematic review and meta-analysis. Lancet Infect Dis. 2012;12:538-549.

20. Lowndes CM, Alary M, Meda $\mathrm{H}$, et al. Role of core and bridging groups in the transmission dynamics of HIV and STIs in Cotonou, Benin, West Africa. Sex Transm Infect. 2002;78(suppl 1):i69-i77.

21. Cote AM, Sobela F, Dzokoto A, et al. Transactional sex is the driving force in the dynamics of HIV in Accra, Ghana. AIDS. 2004;18:917-925.

22. Gomes do Espirito Santo ME, Etheredge GD. Male clients of brothel prostitutes as a bridge for HIV infection between high risk and low risk groups of women in Senegal. Sex Transm Infect. 2005;81: $342-344$.

23. Cohen MS, Muessig KE, Smith MK, et al. Antiviral agents and HIV prevention: controversies, conflicts, and consensus. AIDS. 2012;26: $1585-1598$.

24. Mishra S, Mountain E, Pickles M, et al. Exploring the population-level impact of antiretroviral treatment: the influence of baseline intervention context. AIDS. 2014;28(suppl 1):S61-S72.

25. Kato M, Granich R, Duong D, et al. The potential impact of expanding antiretroviral therapy and combination prevention in Vietnam: towards elimination of HIV transmission. J Acquir Immune Defic Syndr. 2013;63: e142-e149.

26. Delva W, Eaton JW, Meng F, et al. HIV treatment as prevention: optimising the impact of expanded HIV treatment programmes. PLoS Med. 2012;9:e1001258.

27. Williams JR, Alary M, Lowndes CM, et al. Positive impact of increases in condom use among female sex workers and clients in a medium HIV prevalence epidemic: modelling results from project SIDA1/2/3 in Cotonou, Benin. PLoS One. 2014;9:e102643.

28. Nagot N, Meda N, Ouangre A, et al. Review of STI and HIV epidemiological data from 1990 to 2001 in urban Burkina Faso: implications for STI and HIV control. Sex Transm Infect. 2004;80: 124-129.

29. Meda N, Cartoux M, Dabis F, et al. Stabilization of HIV infection rates in urban Burkina Faso, 1995-1999. Int J STD AIDS. 2001;12:460-462.

30. Nagot N, Ouangre A, Ouedraogo A, et al. Spectrum of commercial sex activity in Burkina Faso: classification model and risk of exposure to HIV. J Acquir Immune Defic Syndr. 2002;29:517-521.

31. Nagot N, Ouedraogo A, Ouangre A, et al. Is sexually transmitted infection management among sex workers still able to mitigate the spread of HIV infection in West Africa? J Acquir Immune Defic Syndr. 2005;39: 454-458.

32. Berthe A, Huygens $\mathrm{P}$, Ouattara $\mathrm{C}$, et al. Understanding and reaching young clandestine sex workers in Burkina Faso to improve response to HIV [in French]. Sante. 2008;18:163-173.

33. Berthe A, Huygens P. Communicating with vulnerable women for positive behaviour change: the Yerelon project in Bobo Dioulasso (Burkina Faso) [in French]. Sante. 2007;17:103-109.

34. Vandepitte J, Lyerla R, Dallabetta G, et al. Estimates of the number of female sex workers in different regions of the world. Sex Transm Infect. 2006;82(suppl 3):iii18-iii25.

35. Institut National de la Statistique et de la Demographie Ministere de l'Economie et des Finances 1998. Burkina Faso DHS, 1998-1999. Available at: http://www.measuredhs.com/publications/publication-FR110-DHSFinal-Reports.cfm. Accessed December 10, 2012.

36. Lagarde E, Congo Z, Meda N, et al. Epidemiology of HIV infection in urban Burkina Faso. Int J STD AIDS. 2004;15:395-402.

37. ICF International 2003. Demographic and health Surveys: EDSBF-III Burkina Faso. Available at http://dhsprogram.com/publications/ publication-FR154-DHS-Final-Reports.cfm. Accessed September 15, 2012

38. Bureau d'Appui en Sante Publique 2011. Enquete de surveillance comportementale aupres des groupes a haut risque: travailleuses de sexe (TS) et leurs clients au Burkina Faso: Rapport Final. Burkina Faso. 2011.

39. Konate I, Traore L, Ouedraogo A, et al. Linking HIV prevention and care for community interventions among high-risk women in Burkina Fasothe ARNS 1222 "Yerelon" cohort. J Acquir Immune Defic Syndr. 2011; 57(suppl 1):S50-S54.

40. Lankoande S, Meda N, Sangare L, et al. Prevalence and risk of HIV infection among female sex workers in Burkina Faso. Int J STD AIDS 1998;9:146-150.

41. Lankoande S, Meda N, Sangare L, et al. HIV infection in truck drivers in Burkina Faso: a seroprevalence survey [in French]. Med Trop (Mars). 1998;58:41-46.

42. Buve A, Lagarde E, Carael M, et al. Interpreting sexual behaviour data: validity issues in the multicentre study on factors determining the differential spread of HIV in four African cities. AIDS. 2001;15(suppl 4): S117-S126.

43. Meda N, Ledru S, Fofana M, et al. Sexually transmitted diseases and human immunodeficiency virus infection among women with genital infections in Burkina Faso. Int J STD AIDS. 1995;6:273-277.

44. Institut National de la Statistique et de la Démographie 1993. Measure DHS- Burkina Faso: DHS, 1993, Final Report. Available: http://www. measuredhs.com/pubs/pdf/FR53/FR53.pdf. Accessed December 10, 2012.

45. Huet C, Ouedraogo A, Konate I, et al. Long term virological, immunological and mortality outcomes in a cohort of HIV-infected female sex workers treated with highly active antiretroviral therapy in Africa. BMC Public Health. 2011;11:700.

46. Nagot N, Ouedraogo A, Weiss HA, et al. Longitudinal effect following initiation of highly active antiretroviral therapy on plasma and cervicovaginal HIV-1 RNA among women in Burkina Faso. Sex Transm Infect. 2008:84:167-170.

47. UNAIDS. UNAIDS salutes the leadership of Burkina Faso's President. 2012. Available at: http://www.unaids.org/en/resources/presscentre/ featurestories/2012/december/20121221burkinapresident/. Accessed December 20, 2012.

48. UNAIDS 2011. World AIDS Day Report. Geneva, Switzerland: Joint United Nations Programme on HIV/AIDS (UNAIDS); 2011. Available at: http://www.unaids.org/en/media/unaids/contentassets/documents/ unaidspublication/2011/jc2216_worldaidsday_report_2011_en.pdf. Accessed January 5, 2013. 
49. Jean K, Gabillard D, Moh R, et al. Effect of early antiretroviral therapy on sexual behaviors and HIV-1 transmission risk among adults with diverse heterosexual partnership statuses in Cote d'Ivoire. $J$ Infect Dis. 2014;209:431-440.

50. Lewden C, Gabillard D, Minga A, et al. CD4-specific mortality rates among HIV-infected adults with high CD4 counts and no antiretroviral treatment in West Africa. J Acquir Immune Defic Syndr. 2012;59:213-219.

51. Fox MP, Rosen S. Patient retention in antiretroviral therapy programs up to three years on treatment in sub-Saharan Africa, 2007-2009: systematic review. Trop Med Int Health. 2010;15(suppl 1):1-15.

52. Lawn SD, Little F, Bekker LG, et al. Changing mortality risk associated with CD4 cell response to antiretroviral therapy in South Africa. AIDS 2009;23:335-342.

53. Brinkhof MW, Boulle A, Weigel R, et al. Mortality of HIV-infected patients starting antiretroviral therapy in sub-Saharan Africa: comparison with HIV-unrelated mortality. PLoS Med. 2009;6:e1000066.

54. Mills EJ, Bakanda C, Birungi J, et al. Mortality by baseline CD4 cell count among HIV patients initiating antiretroviral therapy: evidence from a large cohort in Uganda. AIDS. 2011;25:851-855.

55. May M, Boulle A, Phiri S, et al. Prognosis of patients with HIV-1 infection starting antiretroviral therapy in sub-Saharan Africa: a collaborative analysis of scale-up programmes. Lancet. 2010;376:449-457.

56. Wandel S, Egger M, Rangsin R, et al. Duration from seroconversion to eligibility for antiretroviral therapy and from ART eligibility to death in adult HIV-infected patients from low and middle-income countries: collaborative analysis of prospective studies. Sex Transm Infect. 2008;84 (suppl 1):i31-i36.

57. McNairy ML, Howard AA, El-Sadr WM. Antiretroviral therapy for prevention of HIV and tuberculosis: a promising intervention but not a panacea. J Acquir Immune Defic Syndr. 2013;63(suppl 2):S200-S207.

58. Low AJ, Konate I, Nagot N, et al. Cervicovaginal HIV-1 shedding in women taking antiretroviral therapy in Burkina Faso: a longitudinal study. J Acquir Immune Defic Syndr. 2014;65:237-245.

59. Jaquet A, Garanet F, Balestre E, et al. Antiretroviral treatment and quality of life in Africans living with HIV: 12-month follow-up in Burkina Faso. $J$ Int AIDS Soc. 2013;16:18867.

60. Dembele M, Saleri N, Carvalho AC, et al. Incidence of tuberculosis after HAART initiation in a cohort of HIV-positive patients in Burkina Faso. Int J Tuberc Lung Dis. 2010;14:318-323.

61. Vickerman P, Foss AM, Pickles M, et al. To what extent is the HIV epidemic in southern India driven by commercial sex? A modelling analysis. AIDS. 2010;24:2563-2572.

62. Diabate S, Zannou DM, Geraldo N, et al. Antiretroviral therapy among HIV-1 infected female sex workers in Benin: a comparative study with patients from the general population. World J AIDS. 2011;1:94-99.

63. Meda N, Sangare L, Lankoande S, et al. The HIV epidemic in Burkina Faso: current status and the knowledge level of the population about AIDS, 1994-1995 [in French]. Rev Epidemiol Sante Publique. 1998;46:14-23.

64. Vuylsteke B, Semde G, Sika L, et al. HIV and STI prevalence among female sex workers in Cote d'Ivoire: why targeted prevention programs should be continued and strengthened. PLoS One. 2012;7:e32627.

65. Behanzin L, Diabate S, Minani I, et al. Decline in the prevalence of HIV and sexually transmitted infections among female sex workers in Benin over 15 years of targeted interventions. J Acquir Immune Defic Syndr. 2013;63:126-134

66. Laga M, Alary $\mathrm{M}$, Nzila $\mathrm{N}$, et al. Condom promotion, sexually transmitted diseases treatment, and declining incidence of HIV-1 infection in female Zairian sex workers. Lancet. 1994;344:246-248.

67. Eluwa GI, Strathdee SA, Adebajo SB, et al. Sexual risk behaviors and HIV among female sex workers in Nigeria. J Acquir Immune Defic Syndr. 2012;61:507-514.
68. Hallett TB, Gregson S, Mugurungi O, et al. Assessing evidence for behaviour change affecting the course of HIV epidemics: a new mathematical modelling approach and application to data from Zimbabwe. Epidemics. 2009;1:108-117.

69. Boily MC, Lowndes CM, Vickerman P, et al. Evaluating large-scale HIV prevention interventions: study design for an integrated mathematical modelling approach. Sex Transm Infect. 2007;83:582-589.

70. Halperin DT, Mugurungi O, Hallett TB, et al. A surprising prevention success: why did the HIV epidemic decline in Zimbabwe? PLoS Med. 2011;8:e1000414.

71. Institut National de la Statistique et de la Demographie, ICF International 2010. Burkina Faso DHS 2010 - Final Report. Available at: http://www. measuredhs.com/publications/publication-FR256-DHS-Final-Reports.cfm Accessed January 11, 2012.

72. Mtetwa S, Busza J, Chidiya S, et al. "You are wasting our drugs": health service barriers to HIV treatment for sex workers in Zimbabwe. BMC Public Health. 2013;13:698.

73. Stall R, Duran L, Wisniewski SR, et al. Running in place: implications of HIV incidence estimates among urban men who have sex with men in the United States and other industrialized countries. AIDS Behav. 2009;13: 615-629.

74. South African National HIV Prevalence, Incidence and Behaviour Survey, 2012. Cape Town, South Africa: HSRC Press; 2014.

75. McClelland RS, Graham SM, Richardson BA, et al. Treatment with antiretroviral therapy is not associated with increased sexual risk behavior in Kenyan female sex workers. AIDS. 2010;24:891-897.

76. Diabate S, Chamberland A, Zannou DM, et al. Sexual behaviour after antiretroviral therapy initiation in female sex workers and HIVpositive patients from the general population, Cotonou, Benin. AIDS Care. 2013;25:1426-1432.

77. Mawji E, McKinnon L, Wachihi C, et al. Does antiretroviral therapy initiation increase sexual risk taking in Kenyan female sex workers? A retrospective case-control study. BMJ Open. 2012;2:e000565.

78. Kania D, Fao P, Valea D, et al. Low prevalence rate of indeterminate serological human immunodeficiency virus results among pregnant women from Burkina Faso, West Africa. J Clin Microbiol. 2010;48: $1333-1336$

79. Cianci F, Sweeney S, Konate I, et al. The cost of providing combined prevention and treatment services, including ART, to female sex workers in Burkina Faso. PLoS One. 2014;9:e100107.

\section{APPENDIX 1. Composition of the Yérelon Study Group}

Eloi Bahembera, Abdramane Berthé, Minata Coulibaly, MarieChristine Defer, Ramata Diallo, Didier Djagbaré, Charlotte Huet, Issouf Konaté, Florent Ky-Dama, Gilles T. M'Boutiki, Nicolas Méda, Inès Millogo, Nicolas Nagot, Abdoulaye Ouédraogo, Djénéba Ouédraogo, Francois Rouet, Anselme Sanon, Haoua Sawadogo, Roselyne Vallo, and Laurence Vergne [deceased January 2007] (Centre Muraz, Bobo-Dioulasso, Burkina Faso); Philippe Mayaud and Helen A. Weiss (London School of Hygiene and Tropical Medicine, London, United Kingdom); Nicolas Nagot, Vincent Foulongne, Michel Segondy, and Philippe Van de Perre (INSERM U1058 Universite Montpellier-1 and CHU Montpellier, Montpellier, France); JeanBaptiste Andonaba and Adrien Sawadogo (University Hospital of BoboDioulasso, Burkina Faso). 